\title{
The comparison of damage caused by the slug Arion lusitanicus Mabille to diferrent plant species of small-area crops
}

\section{Porównanie uszkodzeń różnych gatunków roślin upraw małoobszarowych powodowanych przez ślimaka Arion lusitanicus Mabille}

\author{
Jan Kozłowski ${ }^{1}$, Monika Jaskulska ${ }^{1}$, Maria Kozłowska²
}

\begin{abstract}
Summary
In the laboratory conditions, the research was carried out on the rate and size of damage to fifteen plant species in small-area crops caused by the Arion lusitanicus slug. Three legumes cultivars of Lupinus angustifolius (Regent, Mirela, Sonet), Lupinus luteus (Parys, Mister, Dukat) and Vicia faba (Bobas, Granit, Olga) were tested. It was shown that the following species Ornithopus sativus, Papaver somniferum, $V$.sativa, Cichorium intybus and L. luteus with the cultivaras Dukat and Parys were most damaged by the slugs, while the least damaged plant species were Pisum sativum, $P$. sativum subsp. arvense, $V$. faba - cultivar Olga and L. angustifolius cultivar Mirela. The blue lupine cultivar Mirela due to a high content of alkaloids was less damaged by $A$. Iusitanicus. The obtained results revealed that the secondary plant metabolites, such as glucosinolates, and terpenoids inhibited feeding by the slugs and as a consequence, reduced the damage to the tested crops.
\end{abstract}

Key words: Arion lusitanicus, small-area crops and pulses, damage of plants

\section{Streszczenie}

W warunkach laboratoryjnych prowadzono badania nad tempem i wielością uszkodzeń piętnastu gatunków roślin upraw małoobszarowych przez ślimaka - ślinika luzytańskiego Arion lusitanicus. Dla testowanych roślin strączkowych określano uszkodzenia trzech odmian łubinu wąskolistnego Lupinus angustifolius (Regent, Mirela, Sonet), łubinu żółtego Lupinus luteus (Parys, Mister, Dukat) oraz bobiku Vicia faba (Bobas, Granit, Olga). Wykazano, że najsilniej uszkadzane przez ślimaki były: seradela siewna Ornithopus sativus, mak lekarski Papaver somniferum, wyka siewna V. sativa, cykoria sałatowa Cichorium intybus oraz łubin żółty L. luteus odmiany Dukat $\mathrm{i}$ Parys. Do roślin najsłabiej uszkadzanych należały groch siewny Pisum sativum, grochopeluszka $P$. sativum subsp. arvense, bobik $V$. faba odmiana Olga oraz łubin wąskolistny L. angustifolius odmiana Mirella. Słabiej uszkadzana przez A. lusitanicus odmiana łubinu wąskolistnego Mirela posiadała wysoką zawartość alkaloidów. Sugeruje to, że te wtórne metabolity roślinne podobnie, jak glukozynolany i terpenoidy hamują żerowanie ślimaków, a w rezultacie ograniczają uszkodzenia roślin.

Słowa kluczowe: Arion lusitanicus, rośliny małoobszarowe i strączkowe, uszkodzenia roślin

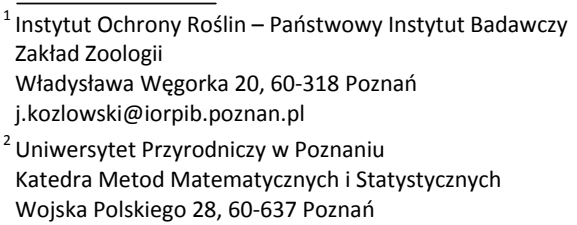




\section{Wstęp / Introduction}

Uprawy małoobszarowe mają coraz większe znaczenie dla produkcji roślinnej i w najbliższych latach mogą stać się cenną alternatywą dla niektórych roślin uprawianych na dużych powierzchniach. Obok konieczności zabezpieczenia chemicznej ochrony tych upraw, istnieje pilna potrzeba oceny stopnia ich zagrożenia przez różne agrofagi w tym również ślimaki. Wśród roślinożerców ślimaki lądowe są znane jako organizmy o szerokim zakresie pożywienia (Glen i Moens 2002; Moens i Glen 2002; Port i Ester 2002; Kozłowski 2003). W uprawach małoobszarowych największe znaczenie ma ślinik luzytański Arion lusitanicus Mabille, 1868 (znany także, jako A. vulgaris Moquin Tandom, 1855), który szybko rozprzestrzenia się w Polsce i jest jednym z najważniejszych szkodliwych ślimaków w ogrodach i uprawach małoobszarowych (Briner i Frank 1998; Kozłowski i Kozłowski 2011).

Celem badań było określenie preferencji pokarmowej tego ślimaka w stosunku do różnych gatunków i odmian roślin oraz ich podatność na uszkodzenia przez ślimaki.

\section{Materiały i metody / Materials and methods}

Wykonano testy bez wyboru na różnych gatunkach roślin strączkowych i innych, które eksponowano na żerowanie ślimaka A. lusitanicus. Spośród roślin strączkowych testowano trzy odmiany łubinu wąskolistnego Lupinus angustifolius (Regent, Mirela, Sonet), łubinu żółtego L. luteus (Parys, Mister, Dukat) i bobiku Vicia faba (Bobas, Granit, Olga) oraz jedną odmianę wyki siewnej $V$. sativa (Hanka). Rośliny rzepaku ozimego Brassica napus (Bazyl) i kapusty pekińskiej Brassica pekinensis (Hilton) były roślinami porównawczymi. Odmiana L. angustifolius Mirela charakteryzowała się wysoką zawartością alkaloidów (1,026\% suchej masy), a odmiana $V$. faba Olga niską zawartością tanin. Badania przeprowadzono w warunkach laboratoryjnych $\left(16^{\circ} \mathrm{C}, \mathrm{RH}\right.$ $70 \pm 3 \%$ i długość dnia 12 godzin). W plastikowych pojemnikach $(26 \times 26 \times 14 \mathrm{~cm})$, zaopatrzonych w otwory wentylacyjne, posadzono w próchniczno-gliniastej ziemi po pięć roślin poszczególnych gatunków i odmian, w fazie 4-6 liści. Następnie w każdym pojemniku umieszczono po jednym wygłodzonym ślimaku o średniej masie 1,36 g. Obserwacje prowadzono, co dwa dni, określając stopień uszkodzenia roślin według pięciostopniowej skali $(0 ; 25$; 50; 75 i 100\% uszkodzonej powierzchni roślin). Dla każdego badanego gatunku i odmiany rośliny wykonano po pięć powtórzeń. Wyniki poddano analizie wariancji i zastosowano test Fischera przy poziomie istotności $\alpha=0,05$.

\section{Wyniki i dyskusja / Results and discussion}

Porównanie wielkości uszkodzeń czternastu gatunków roślin z upraw małoobszarowych wykazało, że istotnie najsilniej uszkodzone po 24 godzinach żerowania $A$. sitanicus były rośliny seradeli siewnej Ornithopus sativus (51,0\%) i rzepaku ozimego B. napus $(48,0 \%)$, a najsłabiej rośliny faceli błękitnej Phacelia tanacetifolia (4,0\%), cykori sałatowej Cichorium intybus $(9,0 \%)$, grochu siewnego Pisum sativum (10,0\%) i łubinu żółtego L. luteus $(10,0 \%)$ (tab. 1). Po pięciu dniach istotnie najsilniej uszkodzone były rośliny O. sativus $(98,0 \%)$ i maku lekarskiego Papaver somniferum (91,0\%), a najsłabiej rośliny P. sativum (20,0\%). Po siedmiu dniach w 100\% uszkodzone zostały rośliny $O$. sativus, po dziewięciu rośliny $P$. somniferum, a po 11 dniach rośliny $C$. intybus i $V$. sativa. Najsłabiej uszkodzone po jedenastu dniach żerowania ślimaków były rośliny $P$. sativum $(37,0 \%)$ i $P$. sativum subsp. arvense (49,0\%). Zaobserwowano, że tempo uszkodzeń niektórych gatunków roślin w fazie 4-6 liści, przez jednego ślimaka o średniej masie 1,36 g było bardzo szybkie. Po 3 dniach gatunki roślin bardziej smakowite dla ślimaków były uszkodzone w około $70 \%$, a po 7-9 dniach w $100 \%$.

W drugim teście, prowadzonym na różnych odmianach $V$. faba, L. angustifolius i L. luteus oraz V. sativa, istotnie najsilniej uszkodzone po 24 godzinach żerowania $A$. lusitanicus były rośliny porównawcze B. napus (tab. 2). Podobne wyniki dla $B$. napus uzyskano po trzech i po pięciu dniach (67,0 i 91,0\% odpowiednio). Po trzech dniach żerowania ślimaków istotnie najsłabiej uszkodzone były rośliny $V$. faba odmiana Olga $(10,0 \%)$ oraz L. angustifolius odmiany Mirela (16,0\%) i Sonet (16,0\%). Po pięciu dniach obok $B$. napus istotnie silnie uszkodzone były rośliny $V$. sativa, L. luteus odmiany Parys i Dukat oraz $B$. pekinensis. Natomiast istotnie słabiej uszkodzone były rośliny $V$. faba odmiany Olga i Granit oraz rośliny trzech odmian L. angustifolius. Tendencja ta utrzymywała się w kolejnych dniach żerowania ślimaków. Po jedenastu dniach, rośliny B. napus i L. luteus odmiany Dukat były uszkodzone w 100\%, podczas gdy najsłabiej uszkodzone były rośliny $L$. angustifolius odmiany Mirela (50,0\%). Tempo uszkodzeń roślin odmian $V$. faba oraz L. angustifolius i L. luteus było nieco wolniejsze niż w pierwszym doświadczeniu. Po pięciu dniach żerowania ślimaków najbardziej smakowite odmiany były uszkodzone w ponad $60 \%$.

Na uwagę zasługuje odmiana L. angustifolius Mirela, najwolniej i najsłabiej uszkadzana przez A. lusitanicus. Odmiana ta charakteryzuje się wysoką zawartością alkaloidów (1,026\% s.m.) w porównaniu do ich zawartości w pozostałych badanych odmianach $L$. angustifolius i L. luteus (poniżej $0,340 \%$ s.m.). Wskazuje to, że alkaloidy zawarte w roślinach mogą hamować żerowanie ślimaków, co potwierdza wcześniejsze wyniki badań innych autorów (Chevalier i wsp. 2000; Aguiar i Wink 2005). Autorzy ci stwierdzali, że rośliny zawierające alkaloidy posiadają repelentne właściwości i są omijane lub słabiej atakowane przez ślimaki lądowe. Alkaloidy występujące w roślinach Fabaceae mogą być toksyczne dla różnych roślinożerców w tym również dla ślimaków. Może to zostać wykorzystane, jako element integrowanej ochrony roślin strączkowych przed ślimakami. 
Tabela 1. Uszkodzenia różnych gatunków roślin z upraw małoobszarowych [\%] przez A. lusitanicus i wyniki testu Fischera przy poziomie $\alpha=0,05$

Table 1. Damages to diferrent species of small-area crops [\%] caused by A. lusitanicus and results of Fisher's test with $\alpha=0.05$

\begin{tabular}{|c|c|c|c|c|c|c|}
\hline \multirow{2}{*}{$\begin{array}{l}\text { Gatunek rośliny (odmiana) } \\
\text { Species of plants (cultivar) }\end{array}$} & \multicolumn{6}{|c|}{$\begin{array}{l}\text { Dni żerowania ślimaków } \\
\text { Days of slug feeding }\end{array}$} \\
\hline & 1 & 3 & 5 & 7 & 9 & 11 \\
\hline Brassica napus (Bazyl) & $48,0 \mathrm{~d}$ & $65,5 \mathrm{c}$ & 75,0 ef & $78,0 \mathrm{~cd}$ & $86,0 \mathrm{~d}$ & $88,5 \mathrm{~d}$ \\
\hline B. pekinensis (Hilton) & $13,5 \mathrm{ab}$ & $24,0 \mathrm{a}$ & $38,0 \mathrm{ab}$ & $43,0 \mathrm{a}$ & $50,0 \mathrm{bc}$ & $60,0 \mathrm{bc}$ \\
\hline Cichorium intybus (Monitor) & $9,0 \mathrm{a}$ & $40,0 \mathrm{ab}$ & $67,0 \mathrm{de}$ & 93,0 de & $99,0 \mathrm{~d}$ & $100,0 \mathrm{~d}$ \\
\hline Glycine max (Aldana) & $19,0 \mathrm{abc}$ & $29,0 \mathrm{a}$ & $39,0 \mathrm{abc}$ & $48,0 \mathrm{ab}$ & $62,0 \mathrm{c}$ & $69,0 \mathrm{c}$ \\
\hline Helianthus annuus & $20,0 \mathrm{abc}$ & $34,0 \mathrm{a}$ & 60,0 cde & $75,0 \mathrm{~cd}$ & $82,0 \mathrm{~d}$ & $91,0 \mathrm{~d}$ \\
\hline Lens esculenta (Anita) & $13,0 \mathrm{ab}$ & $32,0 \mathrm{a}$ & $55,0 \mathrm{bcd}$ & $68,0 \mathrm{bc}$ & $87,0 \mathrm{~d}$ & $96,0 \mathrm{~d}$ \\
\hline Lupinus luteus (Dukat) & $10,0 \mathrm{a}$ & $21,0 \mathrm{a}$ & $28,0 \mathrm{a}$ & $38,0 \mathrm{a}$ & $43,0 \mathrm{abc}$ & $52,0 \mathrm{abc}$ \\
\hline Ornithopus sativus (Emena) & $51,0 \mathrm{~d}$ & $77,0 \mathrm{c}$ & $98,0 \mathrm{~g}$ & $100,0 \mathrm{e}$ & $100,0 \mathrm{~d}$ & - \\
\hline Papaver somniferum (Mieszko) & $33,0 \mathrm{bcd}$ & $61,0 \mathrm{bc}$ & $91,0 \mathrm{fg}$ & 98,0 de & $100,0 \mathrm{~d}$ & - \\
\hline Phacelia tanacetifolia (Stala) & $4,0 \mathrm{a}$ & $20,0 \mathrm{a}$ & $33,0 \mathrm{ab}$ & $45,0 \mathrm{ab}$ & $55,0 \mathrm{bc}$ & $60,0 \mathrm{bc}$ \\
\hline Pisum sativum (Telefon) & $10,0 \mathrm{a}$ & $19,0 \mathrm{a}$ & $20,0 \mathrm{a}$ & $29,0 \mathrm{a}$ & $32,0 \mathrm{a}$ & $37,0 \mathrm{a}$ \\
\hline P. sativum subsp. arvense (Milwa) & $14,0 \mathrm{abc}$ & $27,0 \mathrm{a}$ & $32,0 \mathrm{a}$ & $40,0 \mathrm{a}$ & $41,0 \mathrm{ab}$ & $49,0 \mathrm{ab}$ \\
\hline Sinapis alba (Maryna) & $12,0 \mathrm{a}$ & $25,0 \mathrm{a}$ & $27,0 \mathrm{a}$ & $35,0 \mathrm{a}$ & $45,0 \mathrm{abc}$ & $51,0 \mathrm{abc}$ \\
\hline Vicia sativa (Hanka) & $34,0 \mathrm{~cd}$ & $67,0 \mathrm{c}$ & 81,0 efg & 89,0 cde & $99,0 \mathrm{~d}$ & $100,0 \mathrm{~d}$ \\
\hline
\end{tabular}

Wartości w kolumnach oznaczone tą samą literą nie różnią się istotnie

Values in columns marked with the same letters do not differ significantly

Tabela 2. Uszkodzenia gatunków i odmian roślin strączkowych [\%] przez A. lusitanicus i wyniki testu Fischera przy poziomie $\alpha=0,05$ Table 2. Damages to species and cultivars pulse plants [\%] caused by A. lusitanicus and results of Fisher's test with $\alpha=0.05$

\begin{tabular}{l|c|c|c|c|c|c}
\hline \multirow{2}{*}{$\begin{array}{c}\text { Gatunek rośliny (odmiana) } \\
\text { Species of plants (cultivar) }\end{array}$} & \multicolumn{5}{c}{ Dni żerowania ślimaków na roślinach } \\
& \multicolumn{7}{|c|}{ Days of slug feeding } \\
\cline { 2 - 7 } & 1 & 3 & 5 & 7 & 9 & 11 \\
\hline Brassica napus (Bazyl) & $25,0 \mathrm{c}$ & $67,0 \mathrm{f}$ & $91,0 \mathrm{~d}$ & $96,0 \mathrm{~b}$ & $99,0 \mathrm{~d}$ & $100,0 \mathrm{~d}$ \\
B. pekinensis (Hilton) & $14,0 \mathrm{ab}$ & $45,0 \mathrm{e}$ & $62,0 \mathrm{c}$ & $82,0 \mathrm{~b}$ & $92,0 \mathrm{~d}$ & $96,0 \mathrm{~d}$ \\
Lupinus angustifolius (Mirela) & $4,0 \mathrm{a}$ & $16,0 \mathrm{ab}$ & $30,0 \mathrm{a}$ & $37,0 \mathrm{a}$ & $40,0 \mathrm{a}$ & $50,0 \mathrm{a}$ \\
L. angustifolius (Regent) & $3,0 \mathrm{a}$ & $20,0 \mathrm{abcd}$ & $32,0 \mathrm{a}$ & $45,0 \mathrm{a}$ & $53,0 \mathrm{a}$ & $62,0 \mathrm{ab}$ \\
L. angustifolius (Sonet) & $7,0 \mathrm{ab}$ & $16,0 \mathrm{ab}$ & $32,0 \mathrm{a}$ & $44,0 \mathrm{a}$ & $61,0 \mathrm{abc}$ & $66,0 \mathrm{abc}$ \\
L. luteus (Dukat) & $11,0 \mathrm{ab}$ & $30,0 \mathrm{bcde}$ & $63,0 \mathrm{c}$ & $81,0 \mathrm{~b}$ & $94,0 \mathrm{~d}$ & $100,0 \mathrm{~d}$ \\
L. luteus (Mister) & $11,0 \mathrm{ab}$ & $33,0 \mathrm{cde}$ & $56,0 \mathrm{bc}$ & $77,0 \mathrm{~b}$ & $85,0 \mathrm{~cd}$ & $94,0 \mathrm{~d}$ \\
L. luteus (Parys) & $9,0 \mathrm{ab}$ & $35,0 \mathrm{de}$ & $64,0 \mathrm{c}$ & $83,0 \mathrm{~b}$ & $89,0 \mathrm{~d}$ & $93,0 \mathrm{~d}$ \\
Vicia faba (Bobas) & $5,0 \mathrm{a}$ & $18,0 \mathrm{abc}$ & $34,0 \mathrm{ab}$ & $41,0 \mathrm{a}$ & $54,0 \mathrm{ab}$ & $68,0 \mathrm{bc}$ \\
V. faba (Granit) & $6,0 \mathrm{ab}$ & $21,0 \mathrm{abcd}$ & $29,0 \mathrm{a}$ & $45,0 \mathrm{a}$ & $57,0 \mathrm{ab}$ & $71,0 \mathrm{~cd}$ \\
V. faba (Olga) & $3,0 \mathrm{a}$ & $10,0 \mathrm{a}$ & $17,0 \mathrm{a}$ & $30,0 \mathrm{a}$ & $45,0 \mathrm{a}$ & $59,0 \mathrm{ab}$ \\
V. sativa (Hanka) & $6,0 \mathrm{ab}$ & $35,0 \mathrm{de}$ & $66,0 \mathrm{c}$ & $73,0 \mathrm{~b}$ & $78,0 \mathrm{bcd}$ & $85,0 \mathrm{~d}$ \\
\hline
\end{tabular}

Wartości w kolumnach oznaczone tą samą literą nie różnią się istotnie

Values in columns marked with the same letters do not differ significantly

\section{Wnioski / Conclusions}

1. Spośród piętnastu gatunków roślin z upraw małoobszarowych najsilniej uszkadzane przez ślimaki A. lusitanicus były: $O$. sativus, $P$. somniferum, $V$. sativa i $C$. intybus, podobnie, jak B. napus. Do roślin najsłabiej uszkadzanych należały: $P$. sativum i $P$. sativum subsp. arvense.
2. Wśród badanych odmian roślin strączkowych najsilniej i najszybciej uszkadzane przez $A$. lusitanicus były rośliny L. luteus odmiany Dukat i Parys, podobnie jak rośliny $B$. napus odmiana Bazyl i B. pekinensis odmiana Hilton. Najsłabiej i najwolniej uszkadzane były rośliny $V$. faba odmiana Olga i L. angustifolius odmiana Mirela.

3. Alkalody quinolizydynowe występujące w dużej ilości w roślinach niektórych odmian łubinu mogą być 
potencjalnie ważnymi czynnikami ograniczającymi uszkodzenia roślin przez ślimaki.

4. Na obszarach silnie zasiedlonych przez A. lusitanicus należy unikać uprawy: O. sativus, $P$. somniferum,
V. sativa i C. intybus oraz L. luteus odmian Dukat i Parys.

\section{Literatura / References}

Aguiar R., Wink M. 2005. How do slugs cope with toxic alkaloids? Chemoecol. 15: 167-177.

Briner T., Frank T. 1998. The palatability of 78 wildflower strip plants to the slug Arion lusitanicus. Ann. Appl. Biol. 133: 123-133.

Chevalier L., Desbuquois C., Papineau J., Charrier M. 2000. Influence of the quinolizidine alkaloid content of Lupinus albus (Fabaceae) on the feeding choice of Helix aspersa (Gastropoda: Pulmonata). J. Moll. Stud. 66: 61-68.

Glen D.M., Moens R. 2002. Agriolimacidae, Arionidae and Milacidae as pests in West European cereals. p. 271-300. In: "Molluscs as Crop Pests" (G.M. Barker, ed.). Landcare Res. Ham. New Zealand, CABI Publish., 468 pp.

Kozłowski J. 2003. Stan badań nad metodami zwalczania szkodliwych ślimaków. Post. Nauk Rol. 5 (305): $25-42$.

Kozłowski J., Kozłowski R.J. 2011. Exspansion of the invasive slug species Arion lusitanicus Mabille, 1868 (Gastropoda: Pulmonata: Stylommatophora) and dangers to garden crops - a literature review with some new data. Folia Malac. 19 (4): $249-258$.

Moens R., Glen D.M. 2002. Agriolimacidae, Arionidae and Milacidae as pests in West European oilseed rape. p. 425-439. In: "Molluscs as Crop Pest" (G.M. Barker, ed.). Landcare Res. Ham. New Zealand, CABI Publish., 468 pp.

Port R., Ester A. 2002. Gastropods as pests in vegetables and ornamental crops in Western Europe. p. 337-352. In: "Molluscs as Crop Pests" (G.M. Barker, ed.). Landcare Res. Ham. New Zealand, CABI Publish., 468 pp. 